\title{
Magnetite in Freshwater Magnetotactic Bacteria
}

Richard B. Frankel

Francis Bitter National Magnet Laboratory,

Massachusetts Institute of Technology, Cambridge 02139

RichaRd P. BLAKEMORE

Department of Microbiology,

University of New Hampshire, Durham 03824

RALPH S. WOLFE

Department of Microbiology,

University of Illinois, Urbana 61801

Abstract. A previously undescribed magnetotactic spirillum isolated from a freshwater swamp was mass cultured in the magnetic as well as the nonmagnetic state in chemically defined culture media. Results of Mössbauer spectroscopic analysis applied to whole cells identifies magnetite as a :onstituent of these magnetic bacteria.

Iron-containing bacteria from diverse aquatic environments which orient and swim in a preferred direction in weak (0.1 gauss) magnetic fields (magnetotaxis) have been described (1). Cellular iron is localized in crystals (100 by 150 $\mathrm{nm})$ within these bacteria. Kalmijn and Blakemore (2) demonstrated geomagnetic orientation by similar bacteria in saltmarsh sediments. These workers subsequently obtained evidence through cell remagnetization studies that the bacteria exhibited properties of single domain ferromagnets (3). Thus, the directed swimming response of magnetic bacteria to geomagnetism is a direct one, clearly different from electromagnetic induction exhibited by elasmobranch fishes (4)

Definitive studies of the chemical nature of iron in magnetic bacteria have not been possible because the organisms have not been available in pure culture. Recently, Blakemore (5) isolated a freshwater magnetotactic bacterium. In this report, we describe the results of Mössbauer spectroscopic analyses of magnetic and nonmagnetic whole cells of this isolate cultured in chemically defined media.

The organism was an unclassified magnetotactic spirillum (Fig. 1) designated strain MS-1. It was isolated from sediments of Cedar Swamp, Woods Hole, Massachusetts, and appears to be a new bacterial species by criteria separate from its magnetic properties. Characterization, taxonomy, and details of culturing this organism have been studied (6). Cells of the organism were cultured under microaerobic conditions (the $\mathrm{O}_{2}$ atmosphere over the cultures was initially 6 to $7 \mu M$ ) in a liquid medium containing filtered bog water with succinic acid and sodium nitrate as the principal sources of carbon and nitrogen, respectively. Subsequently, a chemically defined medium lacking bog water was employed. Iron was supplied in this latter culture medium to a final total iron concentration of $1.6 \mathrm{mg} /$ liter, as ferric sulfate and ferric quinate. Results of atomic absorption spectrophotometric analyses indicated that magnetic cells contained 1.5 percent of their dry weight as iron. The cells contained an average of 22 intracellular crystals, each approximately $50 \mathrm{~nm}$ on a side (Fig. 1).

After prolonged culture of strain MS-1 in a medium with less iron, cells grew nonmagnetically. They did not align with stationary external magnetic fields or rotate in response to reversal of the ambient field. From such a culture, a homogeneously nonmagnetic population of cells was obtained by standard microbiological cloning procedures. Nonmagnetic cells lacked intracellular crystals present in magnetic cells and contained less than one-tenth the amount of iron of magnetic cells. In other respects, the two types were similar. Nonmagnetic cells were maintained in a chemically defined medium identical to that used for magnetic cells, except that ferric quinate was deleted. The total iron content of this medium was $3.6 \mu M$.

Cells were mass cultured at $30^{\circ} \mathrm{C}$ in glass carboys having a 10 -liter capacity. They were harvested by continuous flow centrifugation $(15,000 \mathrm{rev} / \mathrm{min})$ at $10^{\circ} \mathrm{C}$. Cell yields were (wet weight) 0.2 to $0.5 \mathrm{~g}$ per liter. Harvested cells were washed three times in distilled water and lyophilized. They were not exposed to magnetic fields stronger than those normally associated with general laboratory conditions (such as a-c motors, pumps, and electrical lines) during growth, harvest, or preparation for analyses.

Mössbauer spectra at room temperature were obtained with $350-\mathrm{mg}$ samples of freeze-dried cells grown under various conditions. Cells analyzed included (i) magnetic cells grown in medium containing bog water, (ii) magnetic cells grown in chemically defined medium containing $29 \mu M$ iron, and (iii) nonmagnetic cells grown in chemically defined medium containing 3.6 $\mu \mathrm{M}$ iron.

No discernible $\gamma$-ray absorption greater than 0.2 percent was observed in nonmagnetic cells (Fig. 2a). The Mössbauer spectrum of magnetic cells grown in medium containing bog water (data not shown) was identical to that of magnetic cells cultured in chemically defined medium (Fig. 2b). The spectrum of Fig. 2b can be characterized as being due primarily to iron in magnetite (7). There are, however, two significant differences between the spectrum in Fig. $2 b$ and the spectrum of stoichiometric magnetite (Fig. 2c). These are (i) an extra absorption area close to $v=0$ (Fig. 2b), which appears to be that of a quadrupole doublet and (ii) a ratio of intensities of the two lowest velocity lines (Fig. 2b) which is closer to $1: 1$ than $1: 2$ as in the spectrum of stoichiometric magnetite (Fig. 2c). The spectrum of $\mathrm{Fe}_{3} \mathrm{O}_{4}$ (magnetite) at room temperature is a superposition of two six-line spectra. One corresponds to $\mathrm{Fe}^{3+}$ in tetrahedral sites and the other to $\mathrm{Fe}^{3+}$ and $\mathrm{Fe}^{2+}$ connected by rapid electron exchange in octahedral sites. Introduction of vacancies in the octahedral sublattice (8) or $\gamma-\mathrm{Fe}_{2} \mathrm{O}_{3}$ on the surface of the particle (9) will cause the relative intensities of the two subspectra to change, with consequent changes in the relative intensities of the two lowest velocity lines. Hence, the iron-containing 


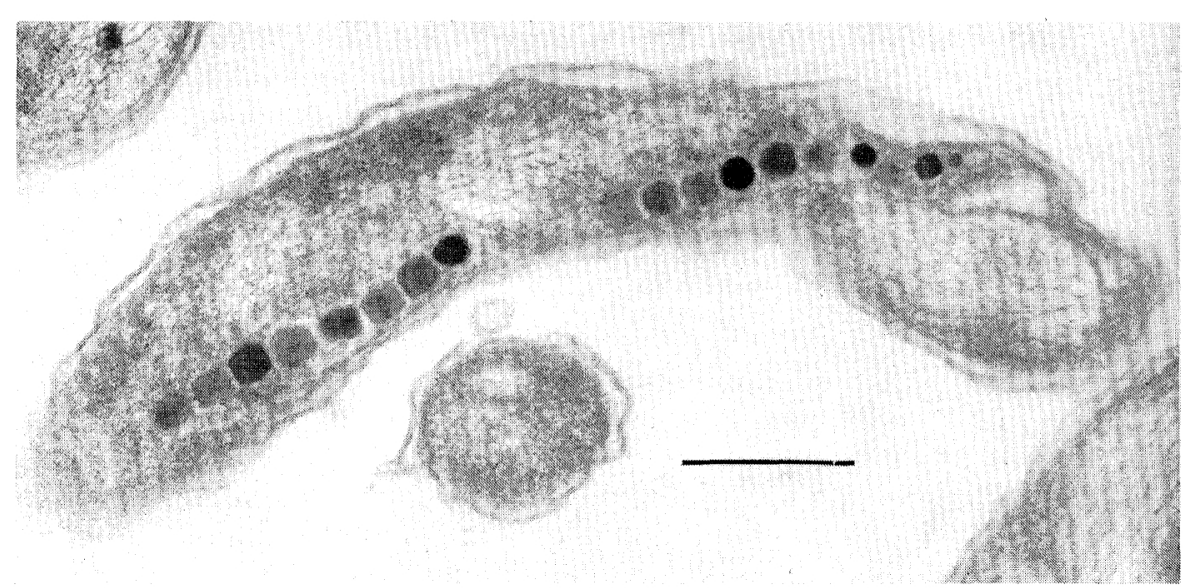

Fig. 1. Electron micrograph of thin-sectioned rnagnetic cells of strain MS-1. Chains of crystals are present within the cell; bar is $250 \mathrm{~nm}$.

material in the freshwater bacteria grown in bog water medium, or in chemically defined medium, can be described as ferrimagnetic $\mathrm{Fe}_{3} \mathrm{O}_{4}$, with either $\sim 4$ percent vacancies in the octahedral sublattice or with a small (several percent) admixture of a $\gamma$ - $\mathrm{Fe}_{2} \mathrm{O}_{3}$ phase. Mössbauer spectra obtained at low temperature and in external magnetic fields are consistent with the identification of the iron-containing material as magnetite (data not shown).

The material producing the extra quadrupole doublet cannot be precisely identified as yet but from the isomer shift it appears to be $\mathrm{Fe}^{3+}$ with oxygen coordination. One possibility is magnetite which is not of sufficient size to be fully magnetized single domain particles, that is, superparamagnetic magnetite (10). Another possibility is an iron-storage protein such as ferritin, which also produces a quadrupole doublet at room temperature (11). However, ferritin itself has not been identified with prokaryotic cells. Finally, it may be another ironstorage compound (12) or an uncharacterized iron-containing compound in which the density of iron is too low to be magnetically ordered at room temperature.

Magnetite crystals with dimensions of those present in strain MS-1 $(50 \mathrm{~nm})$ are within the single domain size range according to the calculations of Butler and

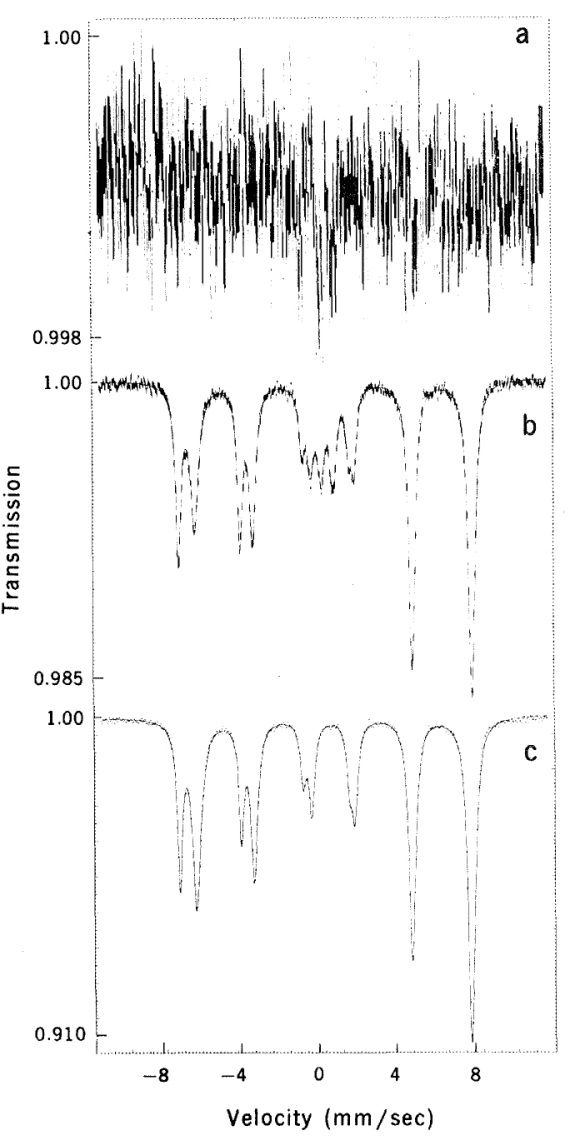

Fig. 2. Mössbauer spectrum at room temperature of (a) $350 \mathrm{mg}$ of freeze-dried nonmagnetic cells of strain MS-1 grown in chemically defined medium, (b) $350 \mathrm{mg}$ of freezedried magnetic cells of strain MS-1 grown in chemically defined medium, and (c) stoichiometric magnetite $\left(\mathrm{Fe}_{3} \mathrm{O}_{4}\right)$, obtained by crushing a freshly prepared interior slice of a magnetite single crystal. Solid lines through the spectra tracings are theoretical least-squares fits to the data, based on Lorentzian line shapes.
Banerjee (13) and the measurements of Dunlop (14). Each cell has a calculated magnetic moment, $M=1.3 \times 10^{-12}$ electromagnetic unit, sufficient to produce alignment in the geomagnetic field, $H=0.5$ gauss, at ambient temperatures $\left(M H=6.6 \times 10^{-13} \quad \mathrm{erg}, \quad k_{\mathrm{B}} T=4.1 \times\right.$ $10^{-14} \mathrm{erg}$, where $k_{\mathrm{B}} T$ is the thermal energy at $T=300 \mathrm{~K}$ ). Thus, the magnetite in these cells constitutes a biomagnetic compass, in confirmation of the original hypothesis of Kalmijn and Blakemore (3).

Magnetite is present in the radular cappings of chitons (15), in the abdomens of live bees (16), and the skulls of pigeons (17). Except for magnetic bacteria, however, it has not been demonstrated that the presence of magnetite in living organisms bears any relation to their orientational responses to external magnetic fields. Thus, the bacteria provide a basis for considering the intriguing possibility that magnetite may also be involved in the orientational responses of some eukaryotic organisms to geomagnetism.

\section{References and Notes}

1. R. P. Blakemore, Science 190, 377 (1975).

2. A. J. Kalmijn and R. P. Blakemore, Proc. Int. Union Physiol. Sci. 13, 364 (1977). 3. Union Physiol. Sci. 13, 364 (1977). Homing, K. Schmidt-Koenig and W. T. Keeton,
Eds. (Springer-Verlag, New York, 1978), p. 344; Eds. (Springer-Verlag, New York, 1978),
see also Sci. Am. 238, 72 (March 1978).

4. A. J. Kalmijn, in Animal Migration, Navigation, and Homing, K. Schmidt-Koenig and W. T. and Homing, K. Schmidt-Koenig and W. T.
Keeton, Eds. (Springer-Verlag, New York, Keeton, Eds.
1978), p. 347.

5. R. P. Blakemore, while working in the laboratory of R. S. Wolfe.

6., D. Maratea, R. S. Wolfe, in preparation. 7. W. Kundig and R. S. Hargrove, Solid State Commun. 7, 223 (1969).

8. V. P. Romanov and V. D. Chercherskii, Sov. Phys.-Solid State 12, 1474 (1970).

9. H. Topsoe, J. A. Dumesic, M. Boudart, J. Phys. (Paris) 12, C6-411 (1974).

10. T. K. McNab, R. A. Fox, A. J. F. Boyle, $J$. Appl. Phys. 39, 5703 (1968).

11. F. A. Fishbach, D. W. Gregory, P. M. Harrison, T. G. Hay, J. M. Williams, J. Ultrastruct. Res. 37, 495 (1971).

12. H. A. Lowenstam and G. R. Rossman, Chem. Geol. 15, 15 (1975).

13. R. F. Butler and S. K. Banerjee, J. Geophys. Res. 80, 4049 (1973).

14. D. J. Dunlop, ibid. 78, 1780 (1973).

15. H. A. Lowenstam, Geol. Soc. Am. Bull. 73, 435 (1962)

16. J. L. Gould, J. L. Kirschvink, K. S. Deffeyes, Science 201, 1026 (1978).

17. C. Walcott, personal communication.

18. We thank D. R. Balkwill for electron microscopy; N. A. Blakemore and D. Maratea for techcopy; N. A. Blakemore and D. Maratea for tech-
nical contributions; and A. J. Kalmijn for inspiration and support. Supported by NSF grants to the Francis Bitter National Magne
Laboratory and by NSF grant PCM 77-12175. 